\title{
THE METABOLISM OF RING-LABELED L-THYROXINE-C ${ }^{14}$ IN VIVO
}

\author{
By C. D. WEST, E. L. SIMONS, M. J. GORTATOWSKI, AND L. F. KUMAGAI
}

(From the Departments of Medicine and Biochemistry, University of Utah College of Medicine, and the Veterans Administration Hospital, Salt Lake City, Utah)

(Submitted for publication January 29, 1963; accepted March 21, 1963)

In the past, investigators have used thyroxine labeled either with $\mathbf{I}^{\mathbf{1 3 1}}$ in the $3^{\prime}, 5^{\prime}$-position or with $\mathrm{C}^{14}$ in the carboxyl position to study the metabolism of thyroxine in vivo. Although these studies have yielded much valuable information, our knowledge about the metabolic fate of the ring structure in thyroxine is incomplete because both the $3^{\prime} 5^{\prime}-\mathrm{I}^{131}$ and the carboxyl- $\mathrm{C}^{14}$ are rapidly removed from thyroxine in vivo by deiodination and decarboxylation. To investigate the metabolic fate of the thyroxine nucleus, L-thyroxine- $\mathrm{C}^{\mathbf{1 4}}$ labeled uniformly in the phenolic ring has been synthesized in our laboratory. Studies on the metabolism of ring-labeled L-thyroxine- $\mathrm{C}^{14}$ following iv administration to rats, dogs, and human subjects are reported in this communication.

\section{METHODS AND MATERIALS}

Synthesis of ring-labeled L-thyroxine- $C^{14}{ }^{1}$ The L-thyroxine- $\mathrm{C}^{14}$ labeled in the phenolic ring was prepared from uniformly labeled phenol- $\mathrm{C}^{14}$ in $2.6 \%$ over-all yield in the following manner: phenol- $\mathrm{C}^{14}$ was converted to 4methoxyphenol- $\mathrm{C}^{14}$ by a series of reactions that included the formation of phenylbenzene sulfonate, nitration to the 4-nitro ester, saponification to 4-nitrophenol, methylation to the ether, reduction of the nitro group to 4methoxyaniline, diazotization of the amino group, and finally hydrolysis of the diazonium salt. The conversion of 4-methoxyphenol- $\mathrm{C}^{14}$ to L-thyroxine- $\mathrm{C}^{14}$ was accomplished by modification of a route developed by Chalmers, Dickson, Elks, and Hems (1) via 3,5-dinitro-N-acety1L-tyrosine ethyl ester. ${ }^{2}$

The L-thyroxine- $\mathrm{C}^{14}$ possessed the following physical constants: melting range 233 to $234^{\circ}$ (with decomposition), $[\alpha] \mathrm{D}^{27}-5.6$, SA $1.55 \mu \mathrm{c}$ per mg. It was compared with nonradioactive and $\mathrm{I}^{131}$-labeled $\mathrm{L}$-thyroxine by decending paper chromatography in three different solvent systems: 2-methyl-2-butanol saturated with $2 \mathrm{~N}$ ammonium hydroxide (TAA), $n$-butanol: $p$-dioxane: $2 \mathrm{~N}$ am-

1 Throughout this manuscript L-thyroxine- $C^{14}$ refers to L-3-[4-(4-hydroxy-3,5-diiodophenoxy-1,2,3,4,5,6-C ${ }^{16}$ ) -3,5diiodophenyl]alanine, unless otherwise specified.

2 Manuscript describing experimental details is in preparation and will be published elsewhere. monium hydroxide (4:1:5 vol/vol) (BDA), and $n$-butanol: acetic acid: water $(4: 1: 5 \mathrm{vol} / \mathrm{vol})$ (BAA). The $R_{\mathrm{f}}$ values were $0.26,0.48$, and 0.85 , respectively. A single radioactive peak corresponding with authentic $\mathrm{L}$-thyroxine was observed in each case. The L-thyroxine- $\mathrm{C}^{14}$ exhibited biological activity equivalent to authentic $\mathrm{L}$-thyroxine when tested by the inhibition of propylthiouracil-induced goiters in rats $(2,3)$ and the suppression of thyroidal $\mathrm{I}^{181}$ uptake (4).

$L$-Thyroxine $\left(3^{\prime}, 5^{\prime}-I^{181}\right)$. The L-thyroxine- $I^{131}$ used in these experiments was labeled in the $3^{\prime}, 5^{\prime}$-positions and was obtained commercially. ${ }^{3}$ It was demonstrated to be radioactively homogeneous by paper chromatography before use.

Experimental subjects. The metabolism of $\mathrm{L}$-thyroxine$\mathrm{C}^{14}$ was investigated in three intact dogs, three intact rats, and nine rats with their common bile ducts cannulated. With the information obtained from these animal experiments, permission was obtained from the Atomic Energy Commission to study the metabolism of $\mathrm{L}$-thyroxine- $\mathrm{C}^{\mathbf{1 4}}$ in two patients with inoperable carcinoma.

For the balance experiments, in which an attempt was made to account for all of the administered radioactivity, rats were kept in gas-tight, all-glass metabolic cages for the separate collection of urine, feces, and expired $\mathrm{CO}_{2}$. The amount of radioactivity in the expired $\mathrm{CO}_{2}$ was measured quantitatively by a modification of the method of Fredrickson and Ono (5). Comparable balance experiments could not be carried out in man and dog because the specific activity of the L-thyroxine- $\mathrm{C}^{\mathbf{1 4}}$ was not high enough to permit accurate measurement of radioactivity in the large quantity of feces and $\mathrm{CO}_{2}$ produced by these species.

The dogs were kept in metabolic cages to allow for the collection of urine and feces separately. The human subjects were housed on the metabolic ward for the entire experimental period.

Between $3 \mu \mathrm{g}(.0046 \mu \mathrm{c})$ and $116 \mu \mathrm{g}(0.180 \mu \mathrm{c})$ of ringlabeled L-thyroxine- $\mathrm{C}^{14}$ dissolved in $0.2 \mathrm{ml}$ of rat serum was administered via the tail vein to rats. With the human subjects and dogs, L-thyroxine- $\mathrm{C}^{14}$ was administered intravenously in doses of 0.4 to $0.5 \mathrm{mg}(0.62$ to $0.78 \mu \mathrm{c})$ dissolved in $5 \mathrm{ml}$ of the experimental subjects' own serum.

A sample of the injected serum was set aside for accurate counting of radioactivity and for paper chromatography. In all experiments, thyroxine was the only radioactive substance in the injected serum, as determined by paper chromatographic analysis.

\footnotetext{
3 Abbott Laboratories, North Chicago, Ill.
} 
TABLE I

Excretion of radioactivity after the administration of ring-labeled L-thyroxine- $C^{14}$ to rats

\begin{tabular}{|c|c|c|c|c|c|c|}
\hline \multirow{2}{*}{$\begin{array}{l}\text { Rat } \\
\text { no. }\end{array}$} & \multirow{2}{*}{$\begin{array}{c}\text { Dura- } \\
\text { tion of } \\
\text { experi- } \\
\text { ment }\end{array}$} & \multirow{2}{*}{$\begin{array}{l}\text { Thyrox- } \\
\text { ine } \\
\text { dose }\end{array}$} & \multicolumn{3}{|c|}{ Percentage of dose in } & \multirow[b]{2}{*}{ Total } \\
\hline & & & $\mathrm{CO}_{2}$ & Urine & Feces & \\
\hline & days & $\mu g$ & & & & \\
\hline $\begin{array}{l}1 \\
2 \\
3\end{array}$ & $\begin{array}{r}8 \\
13 \\
13\end{array}$ & $\begin{array}{r}100 \\
48 \\
48\end{array}$ & 0.1 & $\begin{array}{l}13.3 \\
29.5\end{array}$ & $\begin{array}{l}54.5 \\
63.3 \\
70.7\end{array}$ & $\begin{array}{l}07.9 \\
92.8 \\
88.0\end{array}$ \\
\hline
\end{tabular}

Urine samples were collected at the specified time intervals. Feces were collected in 3-day pools.

Measurement of radioactivity. $\mathrm{C}^{\mathbf{1 4}}$ in urine and plasma was measured quantitatively by liquid scintillation counting, as described by Chen (6). Fecal samples were homogenized, and samples were plated and counted with a Nuclear-Chicago counter, model $\mathrm{C}-115,{ }^{4}$ with an automatic sample changer and a guard tube for low background counting. $\mathrm{I}^{131}$ in samples of urine, feces, plasma, and bile was measured in a well counter by conventional solid scintillation gamma counting techniques.

Paper chromatography. Samples of plasma, bile, and urine were applied directly to Whatman no. 3 filter paper strips and developed routinely in $n$-butanol: $p$-dioxane: $2 \mathrm{~N}$ ammonium hydroxide (4:1:5 vol/vol) (BDA) and $n$-butanol: acetic acid: water $(4: 1: 5 \mathrm{vol} / \mathrm{vol})$ (BAA). In some instances, 2-methyl-2-butanol saturated with $2 \mathrm{~N}$ ammonium hydroxide (TAA) was also used. Radioactive tracings of paper chromatograms were made by a thin-window gas-flow Geiger-Müller detector with a mechanical scanner coordinated to a suitable recorder.

In the double-isotope experiments, ${ }^{131}$-labeled metabolites were distinguished from $\mathrm{C}^{\mathbf{1 4}}$-labeled metabolites by scanning the paper chromatograms before and after the $\mathrm{I}^{131}$ had decayed. For quantitation, samples with both radioactive labels were counted first for $\mathrm{I}^{131}$ with gamma counting techniques, and then for $\mathrm{C}^{14}$ after the $\mathrm{I}^{131}$ had decayed.

\section{RESULTS}

Balance studies. Balance studies, in which an attempt was made to account for all of the administered radioactivity, were carried out only with rats, by use of gas-tight, all-glass metabolic cages. As shown in Table I, nearly all of the administered radioactivity could be accounted for by 13 days after administration. The major excretory route was via the feces; urinary excretion accounted for a smaller but significant proportion of the administered radioactivity. In two rats, the respiratory $\mathrm{CO}_{2}$ was collected continuously for 9 hours after the administration of L-thyroxine-C $\mathrm{C}^{14}$. A significant amount of radioactivity

4 Nuclear-Chicago Corp., Des Plaines, Ill.

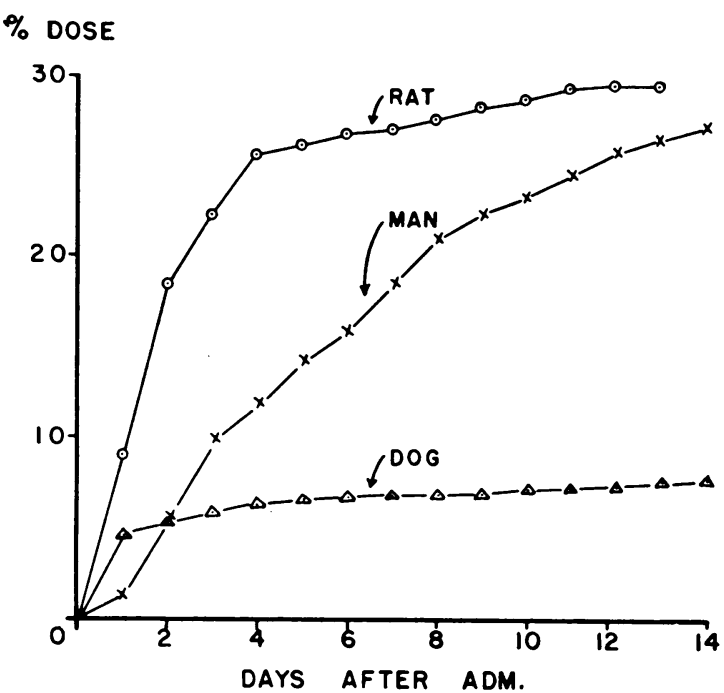

Fig. 1. Cumulative urinary excretion of $\mathrm{C}^{14}$ After THE ADMINISTRATION OF RING-LABELED L-THYROXINE-C ${ }^{14}$ TO RAT, DOG, AND MAN.

( $0.1 \%$ of the dose) could be detected in the expired $\mathrm{CO}_{2}$ only during the first hour.

Urinary excretion of radioactivity. The cumulative excretion of radioactivity in urine for rat, man, and dog is shown in Figure 1. On the basis of percentage of administered dose of radioactivity, man and rat ultimately excreted essentially the same amount in the urine (approximately 30\% of dose), whereas the dog excreted much less (approximately $7 \%$ of the dose). The rate of excretion of radioactivity in the urine was greatest in the rat for the first 4 days, with the excretion tending to level off thereafter, but still continuing at a detectable level for 13 days. In the dog, most of the radioactivity was excreted during the first 24 hours, but detectable amounts of radioactivity were excreted in the urine for 14 days. The rate of urinary excretion was least rapid in man during the first 24 hours, but more sustained thereafter than in the other two species.

Biliary excretion of radioactivity. When ringlabeled L-thyroxine-C ${ }^{14}$ was administered to rats with their common bile ducts cannulated, radioactivity was excreted into the bile, as shown in Figure 2. The cumulative excretion curve reveals a fast component from 0 to 10 hours following injection, after which excretion occurred at a slower constant rate up to 56 hours. That the excretion of radioactivity in the bile was exponential from 10 to 56 hours after administration is 


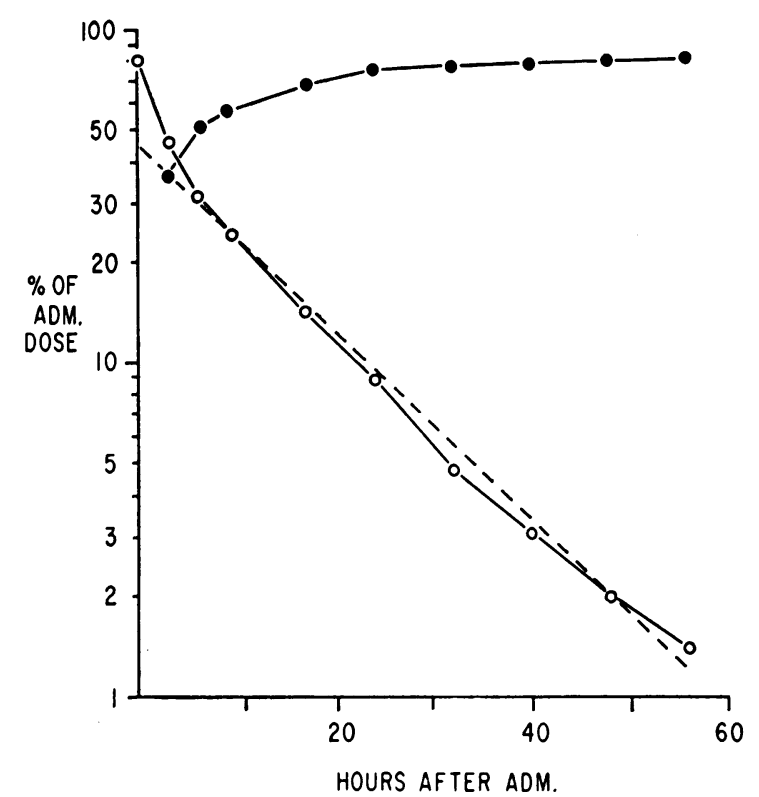

Fig. 2. Biliary excretion of $\mathrm{C}^{14}$ After administraTION OF RING-LABELED L-THYROXINE-C ${ }^{14}$ TO RAT. cumulative excretion of radioactivity. $\mathrm{O}-\mathrm{O}$ : residual $\mathrm{C}^{14}$ curve, representing the amount of $\mathrm{C}^{14}$ destined for biliary excretion remaining in the body with the passage of time. The percentage of dose at any time $x$ on the residual curve is equal to the total amount of $\mathrm{C}^{14}$ excreted in bile minus the cumulative excretion at that time.

suggested by the semilogarithmic plot of the residual $\mathrm{C}^{14}$ ultimately excreted in the bile against time, which was linear (Figure 2). The halftime for this phase of biliary excretion was 10.1 hours.

With complete collection of all bile formed during the experiment, the amount of radioactivity excreted in the urine was approximately $10 \%$ of the administered radioactivity, or about $\frac{1}{3}$ the amount excreted by intact rats. This marked reduction in urinary radioactivity in rats with biliary fistulas suggests that much of the urinary radioactivity excreted by intact animals must arise from material which is initially excreted in the bile and which re-enters the general circulation, presumably through an enterohepatic cycle. An enterohepatic cycle in thyroxine metabolism has been reported previously (7).

\section{Characterization of metabolites of ring-labeled L-thyroxine-C ${ }^{14}$}

Urinary metabolites of ring-labeled L-thyroxine$C^{14}$. In an attempt to identify the radioactive material in the urine of rats given L-thyroxine- $\mathrm{C}^{\mathbf{1 4}}$, small samples (up to $300 \mu$ ) ) of urine were applied directly to paper chromatograms, which were developed in BDA. A single radioactive peak was observed with a mobility corresponding to thyroxine glucuronide (Figure 3 ). When this material was chromatographed in BAA, however, its mobility differed markedly from that expected for thyroxine glucuronide. Further evidence that this unknown metabolite was not thyroxine glucuronide was supplied by the demonstration that no thyroxine was released upon incubation with bacterial $\beta$-glucuronidase. ${ }^{5}$ The behavior of this metabolite upon chromatography in three different solvent systems (BDA, TAA, and BAA) was dissimilar from that of any known free iodinated tyrosines or thyronines.

The possibility that this unknown metabolite might be thyroxine sulfate was considered, and hydrolysis was attempted with sulfatase ${ }^{6}$ and acid hydrolysis ( $\mathrm{pH} 1,15$ hours at room temperature). Only the original unknown material was found following these hydrolyses, suggesting that the unknown urinary metabolite was not thyroxine sulfate.

The unknown urinary metabolite proved to be much more soluble in water than thyroxine, as shown by the observation that the usual methods of extracting thyroxine from aqueous solutions with butanol were unsuccessful in extracting the unknown metabolite from urine. When lyophi-

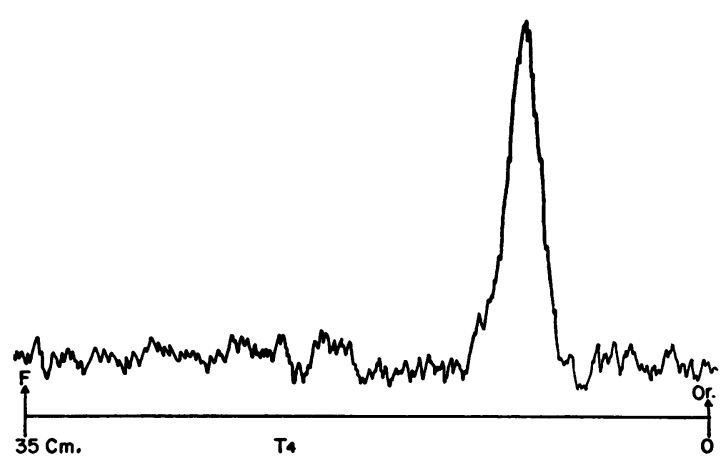

Fig. 3. Radioactive tracing of a paper chromatoGRAM OF RAT URINE AFTER ADMINISTRATION OF RING-LABELED L-TH YROXINE- $\mathrm{C}^{14}$. $\mathrm{F}=$ solvent front $; \mathrm{T}_{4}=$ position of nonradioactive thyroxine standard; Or. $=$ origin.

5 Sigma Chemical Corp., St. Louis, Mo.

${ }^{6}$ Glusilase, Endo Laboratories, Inc., Richmond Hill, N. Y. 


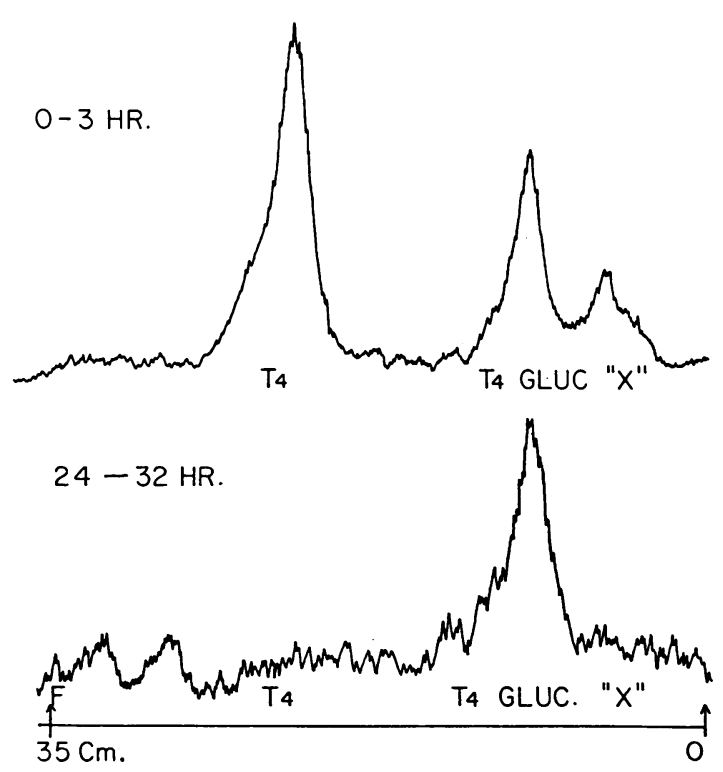

Fig. 4. Radioactive tracings of paper chromatoGRAMS OF RAT BILE AFTER ADMINISTRATION OF RING-LABELED L-THYROXINE-C ${ }^{14}$. Bile was collected from 0 to 3 hours after administration for the upper chromatogram and from 24 to 32 hours for the lower one. $T_{4}=$ thyroxine, $\mathrm{T}_{4}$ gluc. $=$ thyroxine glucuronide, $\mathrm{X}=$ unknown metabolite, $\mathrm{F}=$ solvent front, and $\mathrm{O}=$ origin.

lized urine was extracted continuously in a Soxhlet extractor for 24 hours successively with hexane, ether, ethyl acetate, ethanol, butanol, and water, the final water extract contained most of the radioactivity. So far, it has not been possible to separate this unknown metabolite from the inorganic salts in urine, or to extract the material in sufficient concentration for further characterization.

The radioactivity in the urine of dogs and man could not be concentrated sufficiently for identification of metabolites by paper chromatography. The radioactivity in the urine of these two species, however, was similar in solubility to that from rats.

Biliary metabolites of ring-labeled L-thyroxine$C^{14}$. When bile from rats was applied directly to paper and developed in BDA, three distinct and separate peaks of radioactivity were observed, as shown in Figure 4. The least polar peak corresponded in mobility to thyroxine. This identification was confirmed by chromatography in BAA and TAA. The radioactive peak with intermediate polarity corresponded to thyroxine glucuronide. This identification was confirmed by chromatography in other solvent systems and by the fact that the material was converted quantitatively to free thyroxine when incubated with $\beta$-glucuronidase. The relative proportion of these metabolites in the bile depended upon the time of sampling after injection. Free thyroxine was the major component up to 6 hours after injection, after which thyroxine glucuronide became predominant. Free thyroxine usually could not be detected in bile by 9 hours after injection and thereafter.

The third radioactive material in Figure 4, which barely moved off the origin, accounted for a maximum of $20 \%$ of the total radioactivity in the bile. Its identity has not been established.

Bile samples were not obtained from either man or dog for analysis of $\mathrm{C}^{14}$-labeled metabolites of thyroxine.

Fecal metabolites of ring-labeled L-thyroxine$C^{14}$. Free thyroxine was identified in butanol extracts of rat feces by means of paper chromatography, and accounted for approximately $90 \%$ of the total radioactivity in feces. Attempts to concentrate the $\mathrm{C}^{14}$ radioactivity from the stools of man and dog for identification by paper chromatography were unsuccessful, primarily because of the relatively low level of radioactivity in a large quantity of feces.

Experiments with simultaneous administration of ring-labeled L-thyroxine-C $C^{14}$ and L-thyroxine. $\left(3^{\prime}, 5^{\prime}-I^{131}\right)$. Mixtures of $\mathrm{C}^{14}$ and $\mathrm{I}^{131}$-labeled thy-

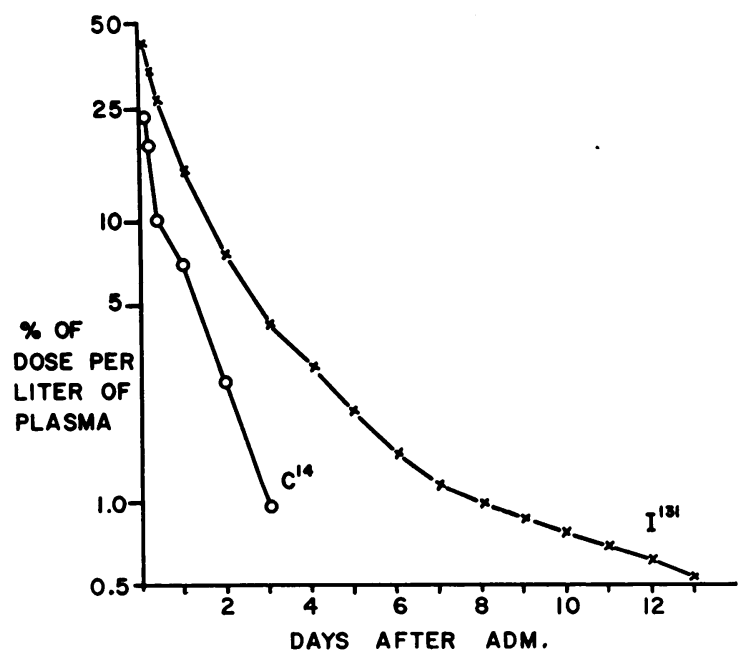

Fig. 5. Plasma decay curves for $C^{14}$ and $I^{131}$ after THE ADMINISTRATION OF $\mathrm{C}^{14}$ - AND ${ }^{131}$-LABELED THYROXINE TO A DOG. 


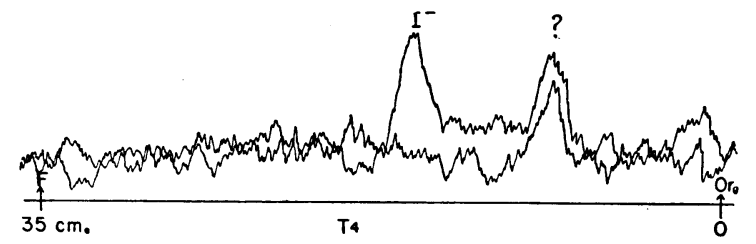

Fig. 6. Superimposed RAdioActive tracings of a PAPER CHROMATOGRAM OF RAT URINE FOLLOWING THE ADMINISTRATION OF $\mathrm{C}^{14}$ - AND I ${ }^{131}$-THYROXINE TAKEN BEFORE AND AFTER THE DECAY OF $I^{181}$. $F=$ front, $T_{4}=$ position of thyroxine standard, $\mathrm{I}^{-}=$iodide, $?=$ unknown $\mathrm{C}^{\mathbf{1 4}}$-labeled urinary metabolite, and Or. = origin.

roxine were administered to experimental animals and to man to determine whether there was any difference in the metabolic fate of the two radioactive labels and to ascertain whether the unknown $\mathrm{C}^{14}$-labeled metabolite in urine, reported above, contained iodine in the $3^{\prime}, 5^{\prime}$-position. After the simultaneous administration of $\mathrm{C}^{14}$ - and $\mathrm{I}^{131}$-labeled thyroxine to human subjects, it was found that the rate of plasma decay for both $\mathrm{C}^{14}$ and $\mathrm{I}^{131}$ was linear on a semilogarithmic plot and essentially identical $\left(t_{\frac{1}{2}}, 6.8\right.$ days). On the other hand, the plasma decay for $\mathrm{I}^{131}$ differed greatly from that for $\mathrm{C}^{14}$ in the dog (Figure 5). The plasma decay for $\mathrm{C}^{14}$ was exponential and much more rapid ( $t_{\frac{1}{2}}=15$ hours) than in the human, but the decay for $\mathrm{I}^{131}$ was nonlinear and much slower. The only $\mathrm{I}^{131}$-labeled substance that could be detected in the plasma of man following the administration of both radioactive labels was free thyroxine, but in dog plasma there were considerable amounts of radioactive iodide, as well as free thyroxine. To eliminate any disturbance in the decay of $\mathrm{I}^{131}$ from plasma due to reutilization of radioactive iodide by the thyroid gland, the dogs were treated with Lugol's solution ( 5 drops, orally, 3 times a day).

In all of the double-isotope experiments, the excretion of $\mathrm{I}^{131}$ in the urine exceeded the excretion of $\mathrm{C}^{14}$. This observation was most striking in the dog, where the excretion of $\mathrm{I}^{131}$ in the urine exceeded the excretion of $\mathrm{C}^{14}$ by a factor of 4 to 5. In man, the excretion of $\mathrm{I}^{131}$ in the urine exceeded the excretion of $\mathrm{C}^{\mathbf{1 4}}$ by a factor of 2 to 3 for the first 3 days after injection. Thereafter, the rates of $\mathrm{C}^{14}$ and $\mathrm{I}^{131}$ excretion in the urine were essentially the same. In intact rats, the excretion of $\mathrm{I}^{131}$ in the urine exceeded the excretion of $\mathrm{C}^{14}$ by about $30 \%$. In rats with their bile ducts can- nulated, the excretion of $\mathrm{C}^{14}$ into the bile exceeded the excretion of $\mathrm{I}^{131}$ by about $10 \%$.

$\mathrm{C}^{14}$-labeled metabolites could not be obtained in sufficient concentration from the urine of dog or man for detection by paper chromatography because of the problems discussed above. However, $\mathrm{I}^{131}$-labeled metabolites were detectable after samples of urine were chromatographed directly on paper. In man, the only $\mathrm{I}^{131}$-labeled metabolite observed in urine was iodide, but in the dog, approximately $20 \%$ of the total urinary $\mathrm{I}^{131}$ was accounted for in thyroxine glucuronide, and another 10 to $15 \%$ was found in an unidentified metabolite which was slightly more polar than thyroxine glucuronide. The remaining $\mathrm{I}^{131}$ (70 to $75 \%$ ) was excreted in the urine as iodide.

When the urine from a rat receiving a mixture of $\mathrm{I}^{131}$ - and $\mathrm{C}^{14}$-labeled thyroxine was analyzed by paper chromatography, the radioactive tracing shown in Figure 6 was obtained. Before the decay of $\mathrm{I}^{131}$, two radioactive peaks were observed. One of these peaks was radioactive iodide, and the other was the material that had been observed before in rats after the administration of L-thyroxine- $\mathrm{C}^{14}$ alone. After all the $\mathrm{I}^{131}$ had decayed, the paper chromatogram was scanned again for radioactivity. The peak of radioactive iodide had now disappeared, but the other peak still remained (Figure 6). Since the size of the radioactive peak of this unknown metabolite was essentially the same after the decay of $I^{131}$ as it was before, it was concluded that it contained only $\mathrm{C}^{14}$ and no $\mathrm{I}^{131}$, indicating loss of iodine from the $3^{\prime}, 5^{\prime}$-positions.

\section{DISCUSSION}

In addition to confirming many of the results obtained in the past with thyroxine labeled in other positions, this study with ring-labeled L-thyroxine$\mathrm{C}^{14}$ has yielded new information on the over-all metabolism of thyroxine and has reopened the question of the importance of the urinary route of excretion. Seven to $30 \%$ of the administered radioactivity in ring-labeled $\mathrm{L}$-thyroxine- $\mathrm{C}^{14}$ was excreted in the urine by three animal species.

Most, if not all, of the $\mathrm{C}^{14}$ in rat urine could be accounted for in a single compound that had lost iodine from the $3^{\prime}, 5^{\prime}$-positions, as indicated by the double-isotope experiments. In the past, studies with $I^{131}$-thyroxine labeled in the $3^{\prime}, 5^{\prime}$-posi- 
tions, or with $\mathrm{C}^{14}$-carboxyl-labeled thyroxine have not indicated the existence of this unknown urinary metabolite, presumably because of loss of the radioactivity by deiodination or decarboxylation, which are known to occur rapidly in vivo $(8,9)$.

The identity of the urinary metabolite arising from ring-labeled $\mathrm{L}$-thyroxine- $\mathrm{C}^{14}$ in rats has not been established in this study, but some of its properties have been determined that permit us to exclude certain known thyroxine metabolites from consideration and to speculate on the probable chemical structure of this compound. After the administration of $\mathrm{I}^{131}$-labeled thyroxine, it has been reported that free thyroxine (10), thyroxine glucuronide (10), and tetraiodothyropyruvic acid (11) are excreted in the urine by rats. We failed to demonstrate any of these compounds in rat urine after the administration of ring-labeled $\mathrm{L}$-thyroxine- $\mathrm{C}^{14}$. This failure might have been due to the low energy of the $\mathrm{C}^{14}$ isotope and the low concentration of these compounds in urine. Certainly the major unidentified $\mathrm{C}^{14}$-labeled metabolite in rat urine was none of these, judged not only by the evidence for loss of iodine from the phenolic ring, but also by the totally different behavior on paper chromatography.

The negligible amount of $\mathrm{C}^{14}$ in the respiratory $\mathrm{CO}_{2}$ of the rat after the administration of ringlabeled L-thyroxine- $\mathrm{C}^{\mathbf{1 4}}$ suggests that the phenolic ring in thyroxine is not broken down in vivo. If this is true, the unknown urinary metabolite would probably be either a phenol or a diphenyl ether, depending upon whether the ether bond is broken. With the phenolic ring of thyroxine labeled, it is impossible to differentiate between these two possibilities.

The solubility of this unknown urinary metabolite in water suggested that it might be a saltforming acid conjugate. However, the failure to obtain any evidence for hydrolysis with glucuronidase, ${ }^{7}$ sulfatase, ${ }^{7}$ and acid argued against conjugation with glucuronic or sulfuric acids. It should be emphasized, however, that conjugation with some other acid, or even with glucuronic or sulfuric acids, cannot be absolutely ruled out on the

\footnotetext{
7 These enzyme preparations were shown to be highly active in the hydrolysis of steroid sulfates and glucuronides.
}

basis of evidence of this type where the chemical nature of the substrate, its enzymatic specificity, and its reaction to acid hydrolysis are entirely unknown.

The possibility that the urinary radioactivity represented urea was considered, in spite of the lack of $\mathrm{C}^{14} \mathrm{O}_{2}$ in the expired air, and ruled out on the basis of chromatographic behavior and the observation that incubation with urease had no effect upon the level of the radioactivity in the urine.

Whether man and dog also excrete this unknown thyroxine metabolite in the urine could not be adequately examined because of the failure to extract and concentrate the material from the large urine volumes excreted by these species. However, both man and dog excreted considerable amounts of $\mathrm{C}^{14}$-labeled material in the urine, with solubility properties similar to those observed in the rat.

Our results on biliary excretion are in agreement with the reports of others that thyroxine glucuronide is the major metabolite of thyroxine excreted in bile $(7,12-14)$. Free thyroxine was demonstrable in bile only for a few hours after injection. No evidence was obtained for the conversion of ring-labeled L-thyroxine- $\mathrm{C}^{14}$ to tetraiodothyroacetic or tetraiodothyropyruvic acids, both of which have been reported in bile after the administration of $\mathrm{I}^{131}$-labeled thyroxine (14-15). Because of the low energy of the $\mathrm{C}^{14}$ isotope and the low concentration of these compounds usually found in bile, however, it is possible that they might have been present but not detected.

A third $\mathrm{C}^{14}$-labeled biliary metabolite, which was highly polar and comprised as much as $20 \%$ of the total radioactivity in bile, has not been identified. The possibility that it might be thyroxine sulfate, which has been reported in bile (16), was considered unlikely, since the material was not altered by acid or enzymatic hydrolysis.

Most of the administered radioactivity in L-thyroxine- $\mathrm{C}^{14}$ was excreted in feces in the form of free thyroxine, an observation which has been previously reported with the use of I $^{131}$-labeled thyroxine (7).

The results obtained with the simultaneous administration of $\mathrm{I}^{131}$ - and $\mathrm{C}^{14}$-labeled thyroxine reveal a species difference in the metabolism of thyroxine. The plasma decay for the two isotopes 
was exponential and identical in man and comparable to those reported for I ${ }^{131}$-labeled thyroxine by Ingbar and Freinkel (17). In the dog, however, $\mathrm{C}^{14}$ was removed from the plasma much faster than $\mathrm{I}^{131}$. Furthermore, the removal of $\mathrm{C}^{14}$ from the circulation was much faster in dog than in man. The first difference could be explained in part by the demonstration of considerable amounts of radioactive iodide in the plasma of dogs, whereas only radioactive thyroxine was observed in humans. This observation suggests that the dog deiodinates thyroxine much faster than does man. However, the dog must also dispose of the $\mathrm{C}^{14}$-labeled phenolic ring structure at a very rapid rate to explain the rapid plasma decay for $\mathrm{C}^{14}$. The demonstration in the double-isotope experiments that dogs excreted other $\mathrm{I}^{131}$-labeled metabolites, such as thyroxine glucuronide and other unidentified metabolites, in addition to iodide in the urine would help explain in part the rapid disposal of the $\mathrm{C}^{14}$ label. Other routes of disposal, however, such as fecal excretion or tissue retention, must also play a major role because total $\mathrm{C}^{14}$ urinary excretion was least in the dog.

One must exercise caution in interpreting the results from this investigation in terms of the normal physiological metabolism of thyroxine. Although ring-labeled L-thyroxine- $\mathrm{C}^{14}$ was prepared with as high a specific activity as possible at the time, it was still necessary to administer doses of thyroxine that equaled or exceeded the total body pool of thyroxine in order to meet the demands of radioactive detection. Under these conditions, abnormally high levels of thyroxine and its metabolites could build up in the circulation and have a tremendous effect on both the nature of the excretory products and the rate at which they are excreted. The shift from the early predominance of free thyroxine in bile to the later appearance of thyroxine glucuronide as the principal biliary metabolite might reflect a transition from an excessively high level to a more nearly physiological concentration of thyroxine in plasma. The unknown deiodinated $\mathrm{C}^{\mathbf{1 4}}$-labeled urinary metabolite was demonstrated in urine only during the first 24 hours. For technical reasons, it could not be ascertained whether the same metabolite was excreted later in urine. It is possible that this unknown metabolite is not excreted under normal physiological conditions.
Abnormally high concentrations would also affect the rate of excretion. The apparent biphasic curves for the excretion of radioactivity into both bile and urine and for the decay of plasma radioactivity could be due to a change in plasma concentration of thyroxine and its metabolites.

Although the results from this study might not apply to the normal physiological disposal of thyroxine, this investigation has yielded valuable information on potential routes of metabolism. The identification of metabolites of thyroxine in excreta, even under unphysiological conditions, means that the body has the necessary enzyme systems to carry out the observed metabolic conversions. To what extent these metabolic pathways are utilized under normal physiological conditions can only be determined when ring-labeled thyroxine with much higher specific activity becomes available, so that tracer doses can be administered without disturbing the normal levels in the body's metabolic pools.

\section{SUM M ARY}

To investigate the metabolic fate of the ring structure of thyroxine, L-thyroxine- $\mathrm{C}^{14}$ with the phenolic ring uniformly labeled was administered intravenously to rat, dog, and man with the following results :

1. Approximately $67 \%$ of the administered $\mathrm{C}^{14}$ was excreted in the feces by rats, with free thyroxine accounting for about $90 \%$ of the total fecal radioactivity.

2. Rat, dog, and man all excreted appreciable amounts of radioactivity in urine, with the dog excreting $7 \%$; man, $25 \%$; and the rat, $30 \%$ of the administered $\mathrm{C}^{14}$ within 2 weeks of injection. A single $\mathrm{C}^{14}$-labeled metabolite, accounting for nearly all of the urinary radioactivity, was isolated from rat urine and partially characterized.

3 . Biliary excretion of the administered radioactivity was substantial ( $83 \%$ of the dose) and rapid ( $t_{\frac{1}{2}}, 10$ hours) in rats. Thyroxine glucuronide was the principal biliary metabolite, along with small amounts of free thyroxine and a third unidentified $\mathrm{C}^{14}$-labeled metabolite.

4 . When a mixture of ring-labeled L-thyroxine$\mathrm{C}^{14}$ and L-thyroxine- $\left(3^{\prime}, 5^{\prime}-\mathrm{I}^{131}\right)$ was given to man, both $\mathrm{C}^{14}$ and $\mathrm{I}^{131}$ were removed exponentially from plasma at essentially the same rate $\left(t_{\frac{1}{2}}, 6.8\right.$ days). With the dog, the rate of removal for $\mathrm{C}^{14}$ 
was much faster than in man ( $t_{1}, 15$ hours), and the plasma decay for $\mathrm{I}^{131}$ was greatly prolonged and nonexponential.

The urinary excretion of $\mathrm{I}^{131}$ exceeded that for $\mathrm{C}^{14}$ in rat, dog, and man, with the dog showing the greatest disproportion. In the rat, it was demonstrated that the $\mathrm{C}^{14}$-labeled urinary metabolite did not contain radioactive iodine.

\section{REFERENCES}

1. Chalmers, J. R., G. T. Dickson, J. Elks, and B. A. Hems. The synthesis of thyroxine and related substances. Part V. A synthesis of L-thyroxine from L-tyrosine. J. chem. Soc. 1949, 3424.

2. Dempsey, E. W., and E. B. Astwood. Determination of the rate of thyroid hormone secretion at various environmental temperatures. Endocrinology 1943, 32, 509.

3. Plamondon, C. A., H. A. Selenkow, J. G. Wiswell, and S. P. Asper, Jr. Studies of thyroxine and some of its analogues. II. The antigoitrogenic properties of thyroxine and triiodothyronine. Bull. Johns Hopk. Hosp. 1958, 102, 88.

4. Money, W. L., R. I. Meltzer, D. Feldman, and R. W. Rawson. The effect of various thyroxine analogues on suppression of $\mathrm{I}^{131}$ uptake by the rat thyroid. Endocrinology 1959, 64, 123.

5. Fredrickson, D. S., and K. Ono. An improved technique for assay of $\mathrm{C}^{14} \mathrm{O}_{2}$ in expired air using the liquid scintillation counter. J. Lab. clin. Med. 1958, 51, 147.

6. Chen, P. S., Jr. Liquid scintillation counting of $\mathrm{C}^{14}$ and $\mathrm{H}^{3}$ in plasma and serum. Proc. Soc. exp. Biol. (N. Y.) $1958,98,546$.

7. Taurog, A., F. N. Briggs, and I. L. Chaikoff. $\mathrm{I}^{131}-$ labeled L-thyroxine. I. An unidentified excretion product in bile. J. biol. Chem. 1951, 191, 29.

8. Klitgaard, H. M., H. J. Lipner, S. B. Barker, and T. Winnick. Pathways of elimination of $\mathrm{C}^{14}-\mathrm{la}$ - beled thyroxine in the rat. Endocrinology 1953, 52, 79.

9. Kot, P. A., and H. M. Klitgaard. Elimination of $\mathrm{C}^{\mathbf{1 4}}$ labeled thyroxine in the bile, urine and expired air of rats in altered thyroid states. Endocrinology 1959, 64, 319.

10. Flock, E. V., and J. L. Bollman. The metabolism of thyroxine and triiodothyronine in the eviscerated rat. J. biol. Chem. 1955, 214, 709.

11. Roche, J., R. Michel, and J. Tata. Sur la nature des combinaisons iodées excreteés par le foie et le rein après administration de L-thyroxine et de L-3:5:3'triiodothyronine. Biochim. biophys. Acta (Amst.) 1954, 15, 500.

12. Flock, E. V., J. L. Bollman, J. H. Grindlay, and G. H. Stobie. Partial deiodination of L-thyroxine. Endocrinology 1961, 69, 626.

13. Roche, J., O. Michel, R. Michel, and J. Tata. Sur l'élimination biliaire de la triiodothyronine et de la thyroxine et sur leur glycuroconjugaison hépatique. Biochim. biophys. Acta (Amst.) 1954, 13, 471.

14. De Gregorio, P., L. C. G. Lobo, R. Michel, and J. Roche. Nature de métabolites des hormones thyroïdienes présents dans la bile et le plasma du rat après administration d'iodures radioactifs. Bull. Soc. Chim. biol. (Paris) 1960, 42, 1213.

15. Roche, J., O. Michel, R. Michel, and J. Tata. On the products of hepatic and renal elimination of thyroxine and triiodothyronine labelled with iodine- 131 in Second Radioisotope Technical Conference, J. E. Johnston, Ed. New York, Academic Press, and London, Butterworths Scientific Publications, 1954, vol. 1 , p. 325 .

16. Roche, J., R. Michel, J. Closon, and O. Michel. Sur la sulfoconjugaison hépatique de la 3,5,5'-triiodo-Lthyronine et la présence d'un ester sulfurique de cette hormone dans la bile et la plasma. Biochim. biophys. Acta (Amst.) 1959, 33, 461.

17. Ingbar, S. H., and N. Freinkel. Simultaneous estimation of rates of thyroxine degradation and thyroid hormone synthesis. J. clin. Invest. 1955, 34, 808. 